CUAD. CONTAB. / BOGOTÁ, COLOMBIA, 17 (44): 421-448 / JULIO-DICIEMBRE 2016 / 421

\title{
Motivación de la labor docente: un estudio de caso de dos programas de contaduría pública en Bogotá*
}

doi:10.11144/Javeriana.cc17-44.mlde

\section{David Andrés Camargo-Mayorga}

Docente de tiempo completo de la facultad de Ciencias Económicas y miembro del grupo de estudios contemporáneos en contabilidad, gestión y organizaciones de la Universidad Militar Nueva Granada. Economista Pontificia Universidad Javeriana y magister en educación de la Universidad Militar Nueva Granada. correo electrónico: david.camargo@unimilitar.edu.co 
Resumen El presente artículo tiene como propósito identificar las motivaciones de los docentes de tiempo completo de dos programas de contaduría pública en Bogotá, en el logro de los objetivos académicos, y toma para el análisis la propuesta motivacional de Frederick Herzberg, Bernard Mausner y Barbara Bloch Snyderman (1959), la cual postula unos factores higiénicos y unos motivadores que influyen en el trabajo; en este caso, en la labor del docente y en su práctica pedagógica. La metodología planteada para el presente trabajo es un estudio de caso cuyo enfoque es hermenéutico e interpretativo; se propone que la investigación tiene un alcance exploratorio pues los procesos de motivación respecto de la pedagogía, específicamente en la práctica de los docentes, son un tema poco abordado. Se identificó que los factores que conforman la motivación de los docentes de ambos programas de Contaduría Pública son diferentes; sin embargo, hay coincidencias. Además, se encontró que algunos de los docentes se sienten motivados, a pesar de estar insatisfechos.

Palabras clave Motivación; docencia; organización educativa

Códigos JEL A23, M12, M41

\section{Motivations of Teaching Work:}

A Case Study of Two Public Accounting Programs in Bogota

\footnotetext{
Abstract The purpose of this article is to identify the motivations full-time teachers of two public accounting programs in Bogota had for the achievement of academic objectives, using for this analysis the motivational proposal of Frederick Herzberg, Bernard Mausner, and Barbara Bloch Snyderman (1959). Said proposal postulates hygienic factors and motivators that influence work, in this case, the work of the teacher and his pedagogical practice. We proposed a case study methodology for this research with a hermeneutic and interpretive approach. We suggest that the research has an exploratory scope since the motivation processes in regards
}

to pedagogy, specifically in the teaching work, are a subject topic scarcely addressed. We identified that the factors that make up the motivation of teachers of both Public Accounting programs are different. However, there are overlapping factors. In addition, some teachers were found to be motivated, despite being dissatisfied.

Keywords motivation; teaching; educational organization

\section{Motivação do labor docente: estudo de caso de dois programas de contabilidade pública em Bogotá}

Resumo o presente artigo tem como propósito identificar as motivações dos docentes de tempo integral de dois programas de contabilidade pública em Bogotá, para alcançar os objetivos académicos, e toma para a análise a proposta motivacional de Frederick Herzberg, Bernard Mausner e Barbara Bloch Snyderman (1959), a qual postula uns fatores higiênicos e motivadores que influenciam o trabalho; neste caso, no labor do docente e na sua prática pedagógica. A metodologia proposta para o presente trabalho é um estudo de caso cujo enfoque é hermenêutico e interpretativo; propõe-se que a pesquisa tem escopo exploratório pois os processos de motivação respeito da pedagogia, especificamente na prática docente, são uma questão apenas abordada. Identificou-se que os fatores que conformam a motivação dos docentes de ambos os programas de Contabilidade Pública são diferentes; no entanto, existem coincidências. Além, encontrou-se que alguns dos docentes ficam motivados, ainda que estiverem insatisfeitos.

Palavras-chave Motivação; docência; organização educativa

\section{Introducción}

En el mundo globalizado y cambiante se hace necesario redefinir los roles y vínculos que 
constituyen el proceso educativo, pues este se sustenta en las relaciones de docentes ${ }^{1}$ y estudiantes. Esta relación está mediada por infinidad de subjetividades que se ponen en juego en la práctica educativa y que devienen de una infinidad de factores psicológicos, actitudinales y motivacionales que actúan en el momento de enseñar y aprender. De este modo, los factores motivacionales son una de las temáticas que más se han estudiado en relación con los factores psicológicos que intervienen en los procesos conductuales de los individuos, lo que en el caso de la pedagogía ha sido visto como un elemento transversal a la práctica didáctica del docente centrada en el estudiante, y que no ha sido amplia y directamente estudiada en relación con la práctica de la labor docente.

Respecto a este problema, Vincent F. Filak y Kennon M. Sheldon (2003), citados por Muhammad Imran Rasheed, Hassan Danial Aslam y Shakeel Sarwar (2010), proponen que la motivación del maestro es fundamental en los procesos de educación a largo plazo, y que de ella dependen el éxito y el rendimiento de cualquier sistema educativo, pues la satisfacción personal de los logros y necesidades incide en la adopción de nuevas técnicas y estrategias didácticas y pedagógicas, que posibilitan el mejoramiento educativo en la educación superior y que propenden a una educación integral, en

1 Docente es quien hace parte de la nómina de una institución educativa y cumple una función profesional en la docencia; profesor es quien dicta clases y cumple un rol pedagógico; educador es aquel que forma seres humanos y cumple un deber social; y maestro es quien se dedica a la formación de mejores personas y ciudadanos y le da una dimensión humana a la enseñanza, haciendo de esto un proyecto de vida (Hernández, 2013). En este artículo, estos términos se tomarán como sinónimos de "docente". cuyo caso, el estudiante debe ser capaz de desarrollar su pensamiento en relación con las necesidades del contexto actual, y en donde el rol del docente como mediador es el mayor potenciador de estas habilidades, pues como señalan Christopher Day y Ruth Leitch (2001, p. 403), citados por Stuart A. Karabenick y AnneMarie Conley (2011, p. 28):

La enseñanza en su mejor momento requiere motivación, el compromiso y la vinculación emocional, por lo cual la interacción y las relaciones que se presentan en el contexto educativo cumplen un papel central en los programas que el maestro desarrolla en los procesos educacionales que están fuertemente ligados con su desarrollo profesional continuo en todas las fases de su vida.

Por tanto, en el contexto pedagógico de la educación superior, el objetivo de este artículo es identificar las motivaciones de los docentes de tiempo completo de dos programas de contaduría pública en Bogotá, que desde los presupuestos de la organización educativa, como un modelo de gestión, tienen en cuenta los procesos y las relaciones sociales de este contexto particular. Desde factores como la motivación, se podrá dar luces en términos educativos al mejoramiento de los programas y universidades en sus procesos, que si bien no son de carácter didáctico y pedagógico, se relacionan directamente con el proceso de enseñanza y aprendizaje pues regulan la conducta de los actores involucrados.

En la literatura contable colombiana, el tema de la educación ha sido ampliamente 
estudiado (León-Paime, 2009), porque según Edison Fredy León-Paime (2008) el interés por esta área se relaciona con la formación de un capital social por parte de los docentes-contadores, que empiezan a trabajar en investigación con una mirada que busca independencia de la reflexión sobre las problemáticas de la empresa y por la curiosidad que generan las temáticas de la cotidianidad docente. Según Hugo A. Macías y Ruth Alejandra Patiño-Jacinto (2014), esta temática hace parte de las líneas de investigación más comúnmente trabajadas en el país, lo que se evidencia en lo publicado por revistas como Lúmina, Cuadernos de Contabilidad y Contaduría Universidad de Antioquia, que hasta 2013 tuvieron como temas comunes de divulgación la contabilidad de gestión, la teoría y la educación contables; en este último tema, la producción se ha abordado desde la perspectiva crítica. En este sentido, Fabiola Loaiza-Robles (2011) concluye que la pedagogía crítica es una valiosa herramienta en la educación contable según lo encontró al caracterizar la incidencia que esta propuesta de enseñanza tiene en la producción académica en el país.

En este escenario, la presente investigación aporta a la comprensión de los factores que desencadenan la motivación del docente contable desde la perspectiva de Frederick Herzberg, Bernard Mausner y Barbara Bloch Snyderman (1959). De estas reflexiones en torno a la motivación desde una mirada organizacional, que tiene en cuenta los aspectos pedagógicos y didácticos en relación con los actores que interactúan en el proceso educativo, este trabajo trata de voltear la mirada a los procesos motivacionales de los docentes, reconociéndolos como ac- tores fundamentales dentro de la organización educativa, pues la motivación se ha visto relegada a procesos pedagógicos en los cuales solo interviene el estudiante, aunque es una de las funciones más importantes del docente en términos didácticos. Este trabajo sigue la línea del estudio de las subjetividades del profesorado, emprendida por Edison Fredy León-Paime (2011), quien concluye que el docente debe ser analizado en su contexto sociohistórico amplio.

Este artículo se estructura de la siguiente manera: en la primera sección se trata el tema de la organización educativa; en la segunda, se aborda la motivación desde la teoría de los dos factores en la satisfacción en el trabajo de Frederick Herzberg, Bernard Mausner y Barbara Bloch Snyderman (1959); en la tercera, se explica la metodología de estudio de caso y su enfoque; en la cuarta, se presentan los resultados del trabajo de campo; y en la quinta y última sección, se hacen algunas consideraciones finales.

\section{La organización educativa}

El término organización educativa hace referencia a la gestión en las instituciones de educación (cultura, gobierno escolar, relaciones laborales, estudiantes, administrativos, etc.). Teniendo en cuenta lo anterior, para entrar a definir sus características y particularidades dentro del ámbito educativo, en primer lugar, es pertinente conceptualizar "educación”, "pedagogía” y “organización” para entender cómo se interrelacionan las teorías pedagógicas con las organizacionales en torno a los procesos educativos. 
En su término amplio, la educación ha existido desde los inicios de la cultura humana y ha permitido el traspaso generacional de la cultura y todo lo que esta implica, por lo cual se ha visto impactada fuertemente por los cambios culturales e institucionales de la sociedad. Desde sus inicios, pasó de ser un tema de instrucción propio de la institución familiar, a ser de carácter social, de lo cual surgen organizaciones especializadas para llevarla a cabo. En sentido amplio, Émile Durkheim (2000, p. 43, 53) define la educación como:

La acción ejercida por las generaciones adultas sobre aquellas que no han alcanzado todavía el grado de madurez necesario para la vida social (...) designa el conjunto de las influencias que la naturaleza, o los demás hombres, pueden ejercer bien sea sobre nuestra inteligencia, bien sea sobre nuestra voluntad, abarcando incluso los efectos indirectos producidos sobre el carácter y las facultades del hombre por cosas cuya meta es completamente diferente: por las leyes, por las formas de gobierno, las artes industriales.

A partir de las reflexiones que genera el acto de educar, surgen la pedagogía y la didáctica. Estas dos envuelven el saber teórico que deviene de la reflexión de los docentes en su práctica, desde las relaciones que entablan con estudiantes, directivos y su entorno en general, hasta los microentornos que rodean el proceso de enseñanza, cuyo fin es el de generar una serie de teorías didácticas y pedagógicas que intentan responder las preguntas sobre ¿por qué, cómo y dónde se enseña?
Los términos educación y pedagogía son problemáticos, dado que uno subyace al otro $y$, por ende, tienden a ser confundidos. A este respecto se aclara que la educación es la acción ejercida sobre los niños por los padres y por los educadores, es decir, se puede dar en todos los ámbitos de la vida social del sujeto y por diferentes medios (televisión, internet, etc.); a diferencia de la pedagogía que es la reflexión acerca del acto de educar, y que consiste en determinar, evidenciar y producir las teorías que conciben el proceso de educación y todas las variables que hacen parte del mismo, en un contexto educativo institucionalizado, es decir, la educación es la materia de reflexión de la pedagogía, pues estriba en una determinada forma de pensar respecto a los elementos de la educación, en contextos específicos (Durkheim, 2000).

Miguel Ángel Pasillas-Valdez (1992) propone que la pedagogía depende de la necesidad y posibilidad de reflexionar sobre la educación, es una disciplina autónoma constituida como un campo del saber referente a la práctica de la educación, cuando la educación pasó de ser una instrucción en un contexto natural a ser la acción de transmitir conocimientos legítimos con un método reconocido y ejercido por quien tiene legitimidad para ello, por lo cual la educación requiere la participación voluntaria del que aprende y la cautela del que educa. De esta forma, el discurso pedagógico tiende a expandirse mientras que los problemas relacionados con la educación aumentan, teniendo en cuenta factores que van más allá de la acción educativa.

Desde el enfoque administrativo, la teoría de la organización es compleja, pues se ha 
constituido por medio de las diferentes relaciones teóricas entre la economía, la sociología, la psicología, la antropología, la ingeniería, la politología e, incluso, por aportes de la historia y el derecho; de ahí proviene una amplia variedad de escuelas, corrientes y enfoques que han generado unas conceptualizaciones teóricas e investigativas (Ramió, 1999).

De modo que hay una multiplicidad de definiciones de organización según la perspectiva y evolución de las escuelas y corrientes teóricas. Para el presente artículo se tomará la definición de organización desde el enfoque de las interacciones entre individuos que proponen Carles Ramió y Xavier Ballart (1993, p. 22):
Esta perspectiva clásica define la organización en función de las interacciones que se producen entre sus miembros (en su caso, de estos con el exterior) y de sus relaciones con los fines y objetivos de la organización, por lo que el objeto de la teoría consiste en analizar la diversidad de comportamientos individuales y los instrumentos que permiten compatibilizar estos con los que requiere la organización para incrementar su eficacia colectiva. Los autores más representativos de esta teoría son Mayo, McGregor, Likert, Herzberg, Argyris y Barnard.

En la tabla 1 se referencian las diferentes teorías y escuelas de la organización.
La administración científica (Henri Fayol, 1916; Luther Gulick \& Lyndall Urwick, 1937; Frederick W. Taylor, 1911).

La corriente estructuralista (Max Weber, 1922).

La escuela de las relaciones humanas (Chris Argyris, 1957; Frederick Herzberg, Bernard Mausner \& Barbara Bloch Snyderman, 1959; Rensis Likert, 1961; Elton Mayo, 1946; Douglas McGregor, 1957).

El sistema cooperativo (Chester Barnard, 1938).

Teoría de la toma de decisiones (Herbert A. Simon, 1947).

El neoestructuralismo (Peter M. Blau \& W. Richard Scott, 1962; Michel Crozier, 1963, 1974; Amitai Etzioni, 1961; Renate Mayntz, 1963).
Frederick W. Taylor propuso el análisis sistemático y de control de la organización, y del estilo de dirección. Su base es el hombre económico racional y parte de una nueva rigurosidad y solidez teórica desde la exposición y sistematización de la experiencia en la empresa.

Max Weber propone que la organización es un sistema ideal que se basa en unas funciones formales establecidas mediante reglas legales, racionales, escritas y exhaustivas.

Propone que el comportamiento humano en las organizaciones no se explica únicamente mediante las motivaciones económicas, pues la motivación y la satisfacción en el trabajo son los elementos centrales que sustentan el comportamiento humano. El hombre deja de ser meramente racional.

Propone que las organizaciones son sistemas cooperativos, y que los actores cooperantes son las fuerzas emitidas por las personas y los grupos que componen la organización, en la cual los individuos dejan de lado sus necesidades personales para socializar en la organización.

Propone que el hombre no posee una racionalidad completa y que esta es instrumental. Se basa en la toma de decisiones dentro de la organización como un proceso complejo, fragmentado e incompleto. Esta teoría busca relacionar el análisis de la dimensión estructural y procedimental de la organización con la dimensión humana. 
La política de gestión (Henry Mintzberg 1973, 1979, 1983).

La teoría de las contingencias (Ludwig von Bertalanffy, 1951; Kenneth Boulding, 1965; Daniel Katz \& Robert L. Kahn, 1966; Talcott Parsons, 1956).

\author{
Propone que la política de gestión debe tener en cuenta unos \\ elementos que son: el trabajo directivo, la estructura organizacional, \\ el poder dentro y fuera de la organización. En un comienzo, Henry \\ Mintzberg consideró la dirección como una ciencia, pero se dio \\ cuenta de que no era tal, por lo que adoptó el discurso soft del \\ management. \\ Explica las características de la organización en relación con las \\ características del entorno y sus relaciones. Entiende la organización \\ como un sistema abierto que está compuesto de subsistemas que \\ generan una compleja red de relaciones.
}

Tabla 1

Teorías y escuelas de la organización

Fuente: elaboración propia, a partir de Santiago García-Álvarez (2015) y Carles Ramió y Xavier Ballart (1993).

Teniendo en cuenta lo anterior, podría decirse que estas teorías de la organización son pertinentes para las instituciones escolares que como organizaciones llevan a cabo el proceso educativo, considerando que en ellas subyacen relaciones entre personas que buscan cumplir un objetivo en común: educar.

Joaquín Gairín-Sallán (1988) plantea que el objeto del estudio de la organización no es el análisis de los elementos en sí mismos (profesor, alumnos, espacio, etc.), sino su perspectiva organizacional. Por tanto, la organización escolar comprende el análisis de realidades formales y no formales, siempre que en ellas haya un proceso sistemático de intervención educativa.

Cabe señalar, así mismo, que aunque la gestión está fundamentalmente relacionada con la actividad de la acción educativa, se aplica a la distribución de funciones o a los procesos de coordinación, y está íntimamente ligada con la forma en que el gerente - o director-dirige e involucra a las personas que tiene a su alrededor y se instaura desde la relación entre las teorías de la administración moderna ${ }^{2}$ y sus aportes, como

2 Para ampliar información al respecto, es posible consultar a Víctor Julio Baltodano-Zúñiga y Ana Rita Badilla- los conceptos del proceso administrativo: planeación, organización, dirección, integración de personal y control, en los cuales los sujetos que componen la institución son el factor fundamental que logra su funcionamiento.

En tal sentido, las diferentes perspectivas administrativas y psicológicas proponen que la motivación es fundamental, aunque en los estudios sobre este tema en la escuela, el foco de intereses haya sido el estudiante, en especial de primaria y secundaria según lo afirman Gerda J. Visser-Wijnveen, Ann Stes y Peter van Petegem (2012). Es importante reconocer que el docente como individuo tiene expectativas y necesidades, características de un ser humano normal, se motiva y desmotiva de acuerdo a las relaciones que se den en su organización y esto afecta necesariamente el cómo se da el proceso educativo, razón por la cual vale la pena revisar cómo se configura el rol docente contable desde sus características y motivación.

Desde sus características, el trabajo de Marlon David García-Jiménez (2016) dilucida algunas cuestiones sobre los modelos de

Alvarado (2009) y Stephen P. Robbins y David A. DeCenzo (2002). 
conocimiento científico adoptados por el profesorado de contaduría pública y encuentra que, en contravía del imaginario social, los docentes no son completamente empiristas, en cambio "vinculan el contenido de la ciencia con conceptos culturales y antropológicos, entienden las limitaciones de la investigación científica, pero destacan la importancia de la teoría y el método científico, para posteriormente definir que la forma en que enseñan está muy lejos de lo que conocen y saben de la ciencia" (p. 101). Además, identifica cuatro modelos de conocimiento científico escolar: i) centrado en el transmisionismo (ortodoxo): para el docente no hay cientificidad contable y se limita a la transmisión de conocimientos prácticos y operativos; ii) desde la noción del campo disciplinar: la cientificidad contable del docente está sesgada por su formación y el área de desempeño, y desdeña la relación de la contabilidad con otros saberes y disciplinas; iii) desde la noción científica de la disciplina: el docente tiene una amplia concepción de la cientificidad contable; y iv) en el marco de la complejidad: el docente tiene una cientificidad contable plural y homogénea.

Por su parte, Edison Fredy León-Paime (2009) plantea que la consolidación de un campo profesional se da por la existencia de una estructura educativa, que le permita mediante los procesos de enseñanza-aprendizaje reproducir y conservar "arbitrariedades" que les dan identidad a las relaciones sociales, lo que recibe el nombre de "profesionalización". Por tanto, las comunidades profesionales surgen del monopolio del saber y el hacer; según León-Paime (2013), la fase de "construcción" de la comunidad profesional contable, en su dimensión educativa, mostró cómo aparecieron las instituciones y titulaciones educativas, y de ahí el surgimiento de la figura del docente como aquel que integraba su labor profesional con la enseñanza. En la fase de "consolidación", manifiesta que se dio una profesionalización del profesor en labores que trascendieron la docencia y terminaron incluyendo la investigación.

En perspectiva histórica, la aparición de la enseñanza de la educación contable y su institucionalización en el marco de la educación superior se consolidan a finales del siglo XIX y principios de siglo XX en Estados Unidos, Reino Unido y Escocia (León-Paime, 2009), pero la profesionalización, según León-Paime (2013), se dio después de la Segunda Guerra Mundial; en los setenta se constituyeron las comunidades temáticas; y en los ochenta y noventa aparecieron los posgrados en contabilidad. Esto muestra lo reciente que es la organización educativa contable.

\section{La motivación}

La motivación es uno de los factores claves que permiten que el individuo se desarrolle en las diversas áreas de su vida, en especial en el área laboral, porque por medio de ella se orientan las acciones hacia unos fines y objetivos que persigue. David C. McClelland (1989) parte de decir que la motivación se refiere tanto a los propósitos conscientes, como a las inferencias relativas a propósitos conscientes que hacemos a partir de la observación de conductas. La motivación tiene qué ver con el porqué de la conducta en contraste con el cómo y el qué, de manera que una respuesta completa a la pregunta ¿por 
qué?, debe incluir todos los determinantes de una conducta y no solo la motivación.

Los determinantes personales de un resultado de conducta pueden ser descompuestos en variables motivacionales, de destreza (o rasgo) y cognitivas (creencias, expectativas o comprensiones) (McClelland, 1989). De esta forma, la motivación se concibe como la trama que sostiene el desarrollo de aquellas actividades significativas, por lo cual en el plano educativo, la motivación se evidencia en la disposición para enseñar y aprender de forma autónoma y continua (Ajello, 2003). La motivación en el ámbito del docente universitario tiene qué ver entonces con lo que León-Paime (2011) denomina las subjetividades del profesorado.

Para este trabajo de investigación, se ahondará sobre la teoría de los dos factores en la satisfacción en el trabajo (Herzberg, Mausner \& Snyderman, 1959).

Esta teoría asume la motivación como algo interno al individuo que se refuerza por factores externos e internos, pues para que un trabajador se sienta motivado no basta con que las condiciones del entorno sean las más adecuadas ya que la tareas, el planteamiento de retos, la autonomía, la responsabilidad y el autocontrol, entre otros factores, influyen en la motivación, es decir, los motivadores como el aumento salarial no son influyentes fuera de un contexto motivacional amplio, pues la calidad de vida para Frederick Herzberg, Bernard Mausner y Barbara Bloch Snyderman (1959) va más allá de las condiciones materiales en las que se desarrolla (por ejemplo, la libertad y la capacidad de decisión y la participación). Por tanto, las necesidades básicas son ante todo de mantenimiento y no de motivación.

Frederick Herzberg, Bernard Mausner y Barbara Bloch Snyderman (1959) realizaron un estudio en el cual por medio de entrevistas lograron identificar que los factores relacionados con la satisfacción no eran los mismos que los que corresponden a la insatisfacción; de este modo, propusieron que la relación satisfacción-insatisfacción no estaba enmarcada en un paradigma dual, en el cual un factor satisfecho reduce la insatisfacción y viceversa, pues no son opuestos y cada uno tiene sus factores.

Los dos factores que según Frederick Herzberg, Bernard Mausner y Barbara Bloch Snyderman (1959) motivan e insatisfacen a los empleados son:

- Motivadores: estos factores son los que satisfacen al individuo en el lugar de trabajo, por lo cual son propios del mismo, es decir, su contenido está exclusivamente en el lugar de trabajo. Estos son los únicos que pueden llevar a la satisfacción en el ambiente laboral y son: el logro, el reconocimiento, la responsabilidad, el desarrollo profesional, el desarrollo personal, etc. Los motivadores tienen como fin último motivar y si no son implementados, no generan insatisfacción siendo neutros.

- Factores de higiene: estos están relacionados únicamente con la insatisfacción, y nunca podrán llevar a la motivación; por tanto, pueden tener un efecto preventivo frente a la satisfacción, pero nunca motivarán las tareas del sujeto en sí. Frederick Herzberg, Bernard Mausner y Barbara Bloch Snyderman (1959) evidenciaron que 
estos factores se relacionan directamente con las condiciones del contexto de trabajo, y entre estos están las políticas de la organización, las relaciones con los compañeros, el salario, etc.

Según esta teoría, los procesos de motivación y satisfacción se dan por separado y de forma simultánea, de modo que un trabajador puede estar motivado pero insatisfecho al mismo tiempo.

La importancia de esta teoría radica en que propone un alejamiento de la visión tradicional de la motivación, la cual se centra en satisfacer los factores de higiene, como las modificaciones físicas, las políticas organizativas, etc., y entiende que aunque estos menguan la insatisfacción no motivan al individuo. Pues si se quiere motivar, se deben rediseñar estrategias que aumenten la motivación teniendo en consideración las oportunidades de desarrollo de logro, por medio de la autonomía, la responsabilidad y el reconocimiento personal, con énfasis en los motivadores internos del individuo.

Desde esta perspectiva, la motivación se centra entonces en aquellos factores que permiten el desarrollo profesional, a pesar de factores que aunque influyen en la satisfacción, no motivan al individuo como tal. Esta teoría permite identificar cuáles son los factores que motivan al docente dentro del desarrollo de su profesión, desde una gestión educativa que reconoce que la motivación va más allá del cumplimiento de unas necesidades básicas y de la satisfacción de necesidades que no tienen en cuenta la subjetividad del individuo.

En este aspecto se hace necesario identificar cuáles son los motivadores de los docentes en la educación superior, pues de esta disposición hacia el trabajo depende el mejoramiento continuo de los procesos educativos, ya que las técnicas, estrategias didácticas y pedagógicas, y la participación constante en procesos académicos en la profesión docente están íntimamente

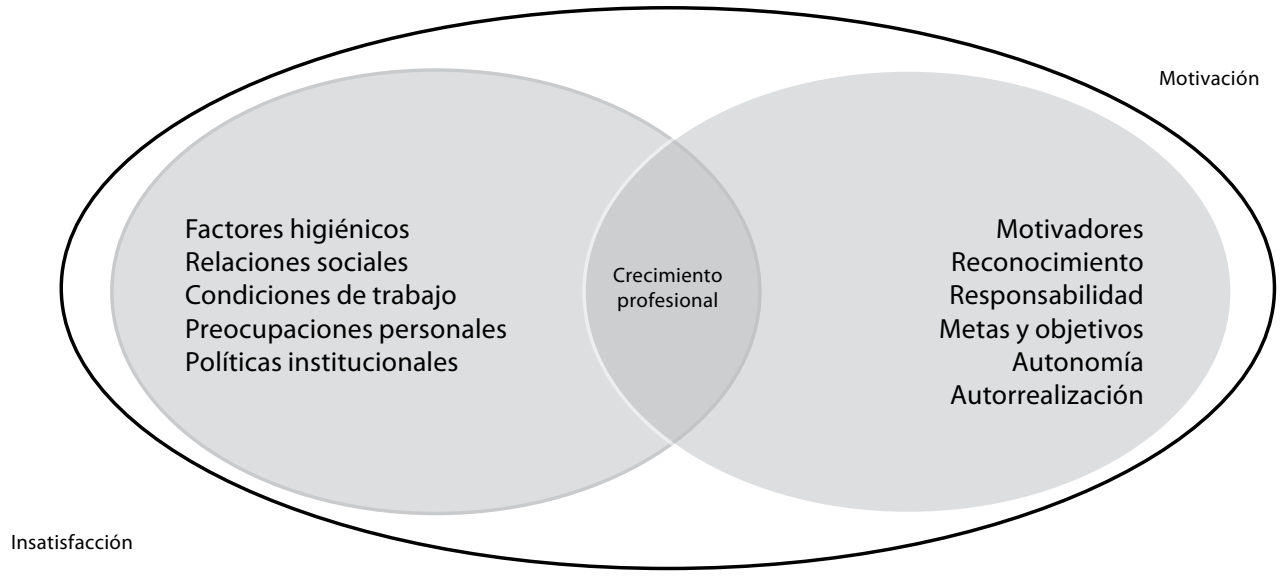

Gráfico 1

Teoría de los factores de Herzberg, Mausner y Snyderman

Fuente: elaboración propia a partir de Frederick Herzberg, Bernard Mausner y Barbara Bloch Snyderman (1959). 
relacionadas con la actitud y la aptitud con las que asume la labor de educar, de lo cual se infiere que una buena disposición y motivación en este ámbito permitirán que los procesos de enseñanza aprendizaje mejoren, ya que la docencia tiene como característica principal la relación con los otros, mediante procesos de comunicación que reconozcan en el otro un sujeto activo capaz de crear conocimiento.

En este sentido, los motivadores constituyen el eje de la motivación de los docentes en educación superior, ya que un docente motivado representa un estudiante motivado.

\section{Metodología}

Para este estudio se optó por el enfoque hermenéutico interpretativo, ya que este permite la interpretación de los significados que son propios del grupo de estudio (docentes contables), lo que dio a la investigación un alcance real que posibilita la eventualidad de factores de mejora en los procesos educativos en el contexto institucional y social (Martínez-González, 2007).

El alcance exploratorio permite la identificación de conceptos o variables novedosas para la descripción de situaciones o eventos casi inexplorados (Dahnke, 1989), lo que da cuenta de los diferentes factores vinculados al problema de investigación (Cazau, 2006), al determinar tendencias, contextos y posibles situaciones de estudio, que desde el enfoque hermenéutico interpretativo facilitan un análisis integral del fenómeno a estudiar (Hernández-Sampieri, Fernández-Collado \& Baptista-Lucio, 2006).

Por esto se determinó que la investigación se llevaría a cabo por medio del método del es- tudio de caso de dos programas de contaduría pública acreditados en alta de calidad de las universidades $\mathrm{U}^{3}$ y $\mathrm{U} 2^{4}$ en la ciudad de Bogotá.

El estudio de caso es instrumental, debido a que la elección del grupo de estudio se determinó para la comprensión del fenómeno de la motivación desde las particularidades de la colectividad seleccionada, es decir, no se pretende develar las características específicas de la población sino el fenómeno de estudio de la motivación en los docentes universitarios en general (Stake, 2007). Desde el paradigma hermenéutico exploratorio, esto permitió la interpretación del fenómeno para abrir el campo del estudio, porque desde la determinación de un grupo de docentes, programas e instituciones específicos, desde esta especificidad, no se posibilita la generalización de los resultados y conclusiones a otros casos, sobre la premisa de que cada caso es único e irrepetible, por sus peculiaridades y circunstancias según los contextos específicos, la cultura y en general la sociedad (Martínez-González, 2007).

El análisis y la recolección de la información se hicieron mediante la triangulación de datos, pues esta permitió la correlacion de múltiples métodos de recolección y análisis de la información, para abordar el fenómeno de la motivación desde la combinación de dos o más teorías, fuentes de datos y métodos de investigación, que relacionan los datos levantados durante el proceso, lo que aporta más confiablidad al estudio al revelar las debilidades y concordancias entre los mismos (Okuda-Benavides \& Gómez-Restrepo, 2005). El gráfico 2 ilustra la triangulación de datos para esta investigación.

3 Universidad pública acreditada institucionalmente. 


\section{2 / VOL. 17 / NO. 44 / JULIO-DICIEMBRE 2016}

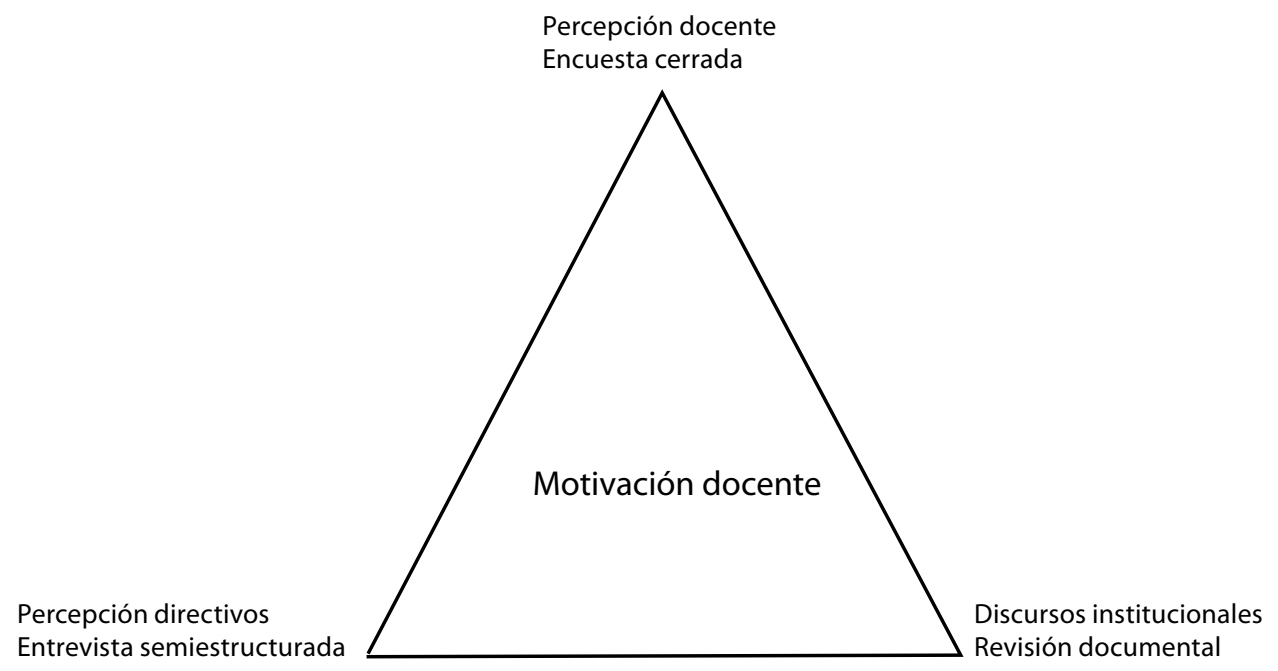

Gráfico 2

Triangulación de datos

Fuente: elaboración propia

Teniendo en cuenta el enfoque interpretativo $^{5}$, se diseñaron los siguientes instrumentos para la triangulación:

- Entrevista semiestructurada: es una conversación cuyo propósito definido se hace en función del problema a investigar. La entrevista semiestructurada se caracteriza por la utilización de preguntas abiertas, por lo que es flexible, debido a que la persona responde con sus propias palabras, pero en el marco de referencia de la temática que se ha formulado.

Para este trabajo, la entrevista se diseñó agrupando las categorías de análisis utilizadas para la encuesta dirigida a docentes (tabla 2). Se estructuró alrededor de 5 preguntas abiertas que relacionaban las categorías mencionadas. Esta se

5 Para más información sobre investigaciones en el área contable desde el enfoque interpretativo, Hugo A. Macías (2013). hizo únicamente a los dos directores de los programas de contaduría pública de las universidades seleccionadas para el estudio de caso.

\begin{tabular}{ll}
\hline \multicolumn{1}{c}{ Categorías de análisis } \\
\hline 1. Pregunta & $\begin{array}{l}\text { Clima laboral } \\
\text { Condiciones ambientales en el puesto } \\
\text { de trabajo } \\
\text { Ergonomía }\end{array}$ \\
2. Pregunta & $\begin{array}{l}\text { Posibilidades de creatividad e iniciativa } \\
\text { Compañeros de trabajo }\end{array}$ \\
3. Pregunta & $\begin{array}{l}\text { Funciones de trabajo } \\
\text { Remuneración }\end{array}$ \\
4. Pregunta & $\begin{array}{l}\text { Reconocimiento } \\
\text { Satisfacción }\end{array}$ \\
\hline
\end{tabular}

Tabla 2

Categorías de análisis entrevista

Fuente: elaboración propia

- Encuesta cerrada de escala Likert: constituyó la segunda parte de recolección de la información. Esta se hizo mediante el diseño e 
implementación de una encuesta con preguntas cerradas para responder de forma específica. El instrumento fue explicativo, al permitir identificar cuáles fueron los factores determinantes del fenómeno de la motivación, a partir de Frederick Herzberg, Bernard Mausner y Barbara Bloch Snyderman (1959). Se aplicó a 19 profesores de la U1 y a 5 de la U2 que correspondían a la totalidad de la planta profesoral de tiempo completo de ambas instituciones. Dado que "La investigación con estudio de casos no es una investigación de muestras. El objetivo primordial del estudio de un caso no es la comprensión de otros. La primera obligación es comprender este caso" (Stake, 2007, p. 17).

La encuesta constó de 48 preguntas cerradas, que se agruparon en las categorías referidas en la tabla 3.

\begin{tabular}{l} 
Categorías de análisis \\
\hline Clima laboral \\
Condiciones ambientales en el puesto de trabajo \\
Ergonomía \\
Posibilidades de creatividad e iniciativa \\
Compañeros de trabajo \\
Funciones de trabajo \\
Remuneración \\
Reconocimiento \\
Satisfacción
\end{tabular}

Tabla 3

Categorías de análisis encuesta Fuente: elaboración propia

Con el enfoque interpretativo, la validación de los instrumentos se hizo teniendo en cuen- ta su validez interna y externa (Monje-Álvarez, 2011); esta requirió una prueba piloto aplicada a 5 docentes (pertenecientes a una universidad privada diferente a la U2) para la encuesta, y de 4 docentes expertos para la entrevista, que determinaron el estado del instrumento y la pertinencia de la investigación. Los docentes para la implementación de la prueba piloto se escogieron por conveniencia y por tener características similares a la población final que se encuestó y entrevistó, para evitar errores sistemáticos en la interpretación y descripción de los datos.

\section{Resultados}

Se identificó que los factores que conforman la motivación de los docentes de ambos programas de contaduría pública son diferentes; sin embargo, hay coincidencias.

Los docentes de ambas universidades manifiestan que sus ingresos provienen principalmente de la actividad docente (gráfico 3), en salarios que oscilan mayoritariamente entre los 3 y 8 salarios mínimos (gráfico 4 ).

En general, coinciden en que su remuneración comparada con otros oficios diferentes al de profesor es menor (gráfico 5).

Manifiestan también que su satisfacción general con el trabajo como docentes de tiempo completo es alta (gráfico 6), aunque al momento de hacer comparaciones con otras universidades en que han laborado, los profesores de la U1 no están tan satisfechos (gráfico 7).

En la U1, los docentes manifiestan insatisfacción frente a sus condiciones ambientales de su trabajo y su remuneración, que constituyen 


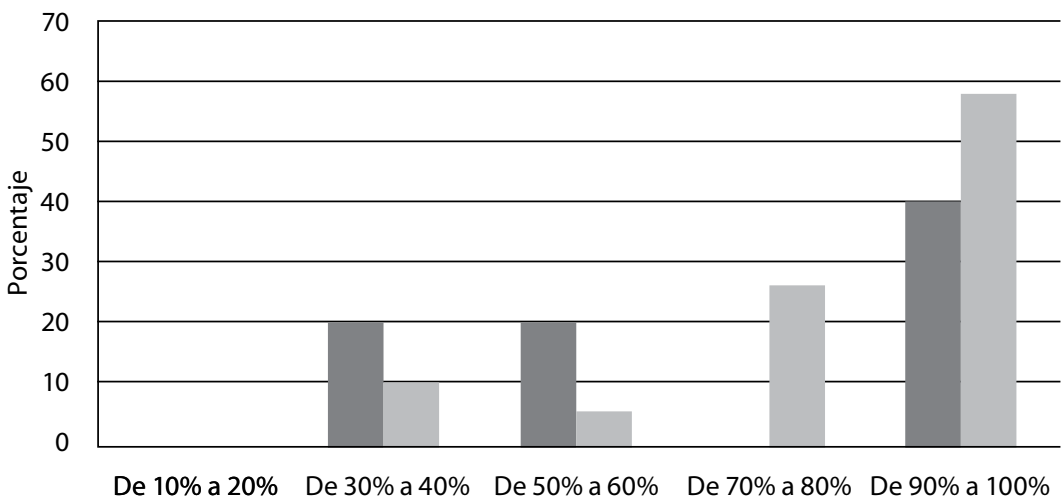

Gráfico 3

Porcentaje de ingresos provenientes de la actividad docente

Fuente: elaboración propia, a partir de datos de la investigación

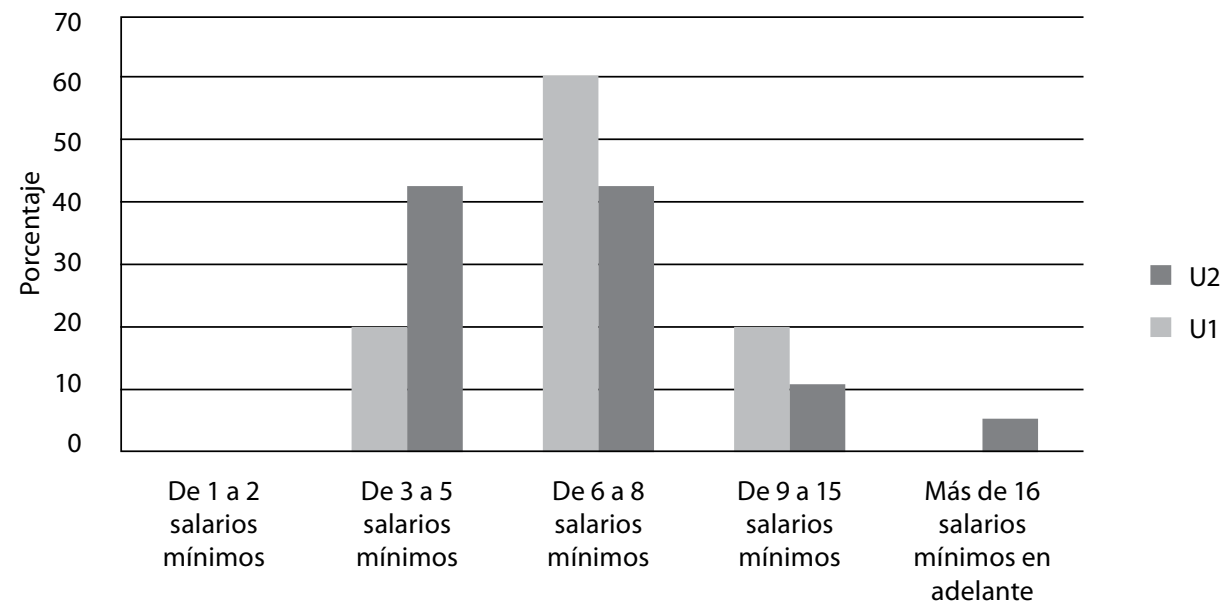

Gráfico 4

Remuneración promedio mensual

Fuente: elaboración propia a partir de datos de la investigación 


\section{MOTIVACIÓN DE LA LABOR DOCENTE / D. CAMARGO / 435}

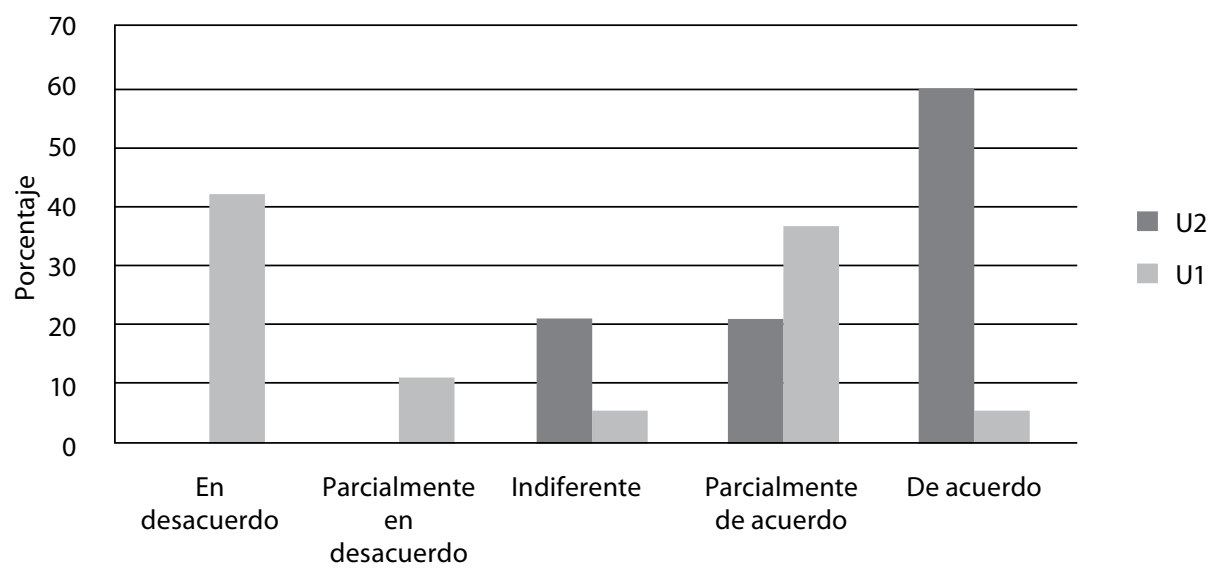

\section{Gráfico 5}

¿Considera que su trabajo en comparación con otros oficios está bien remunerado? Fuente: elaboración propia, a partir de datos de la investigación

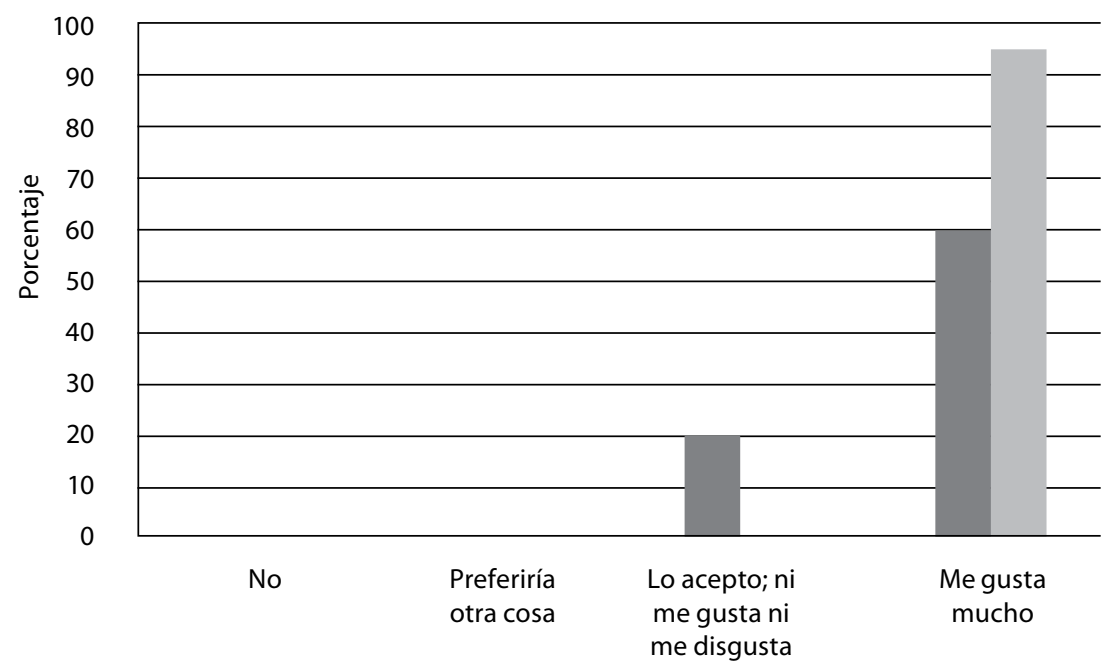

Gráfico 6

¿Le gusta ser profesor de tiempo completo?

Fuente: elaboración propia, a partir de datos de la investigación 


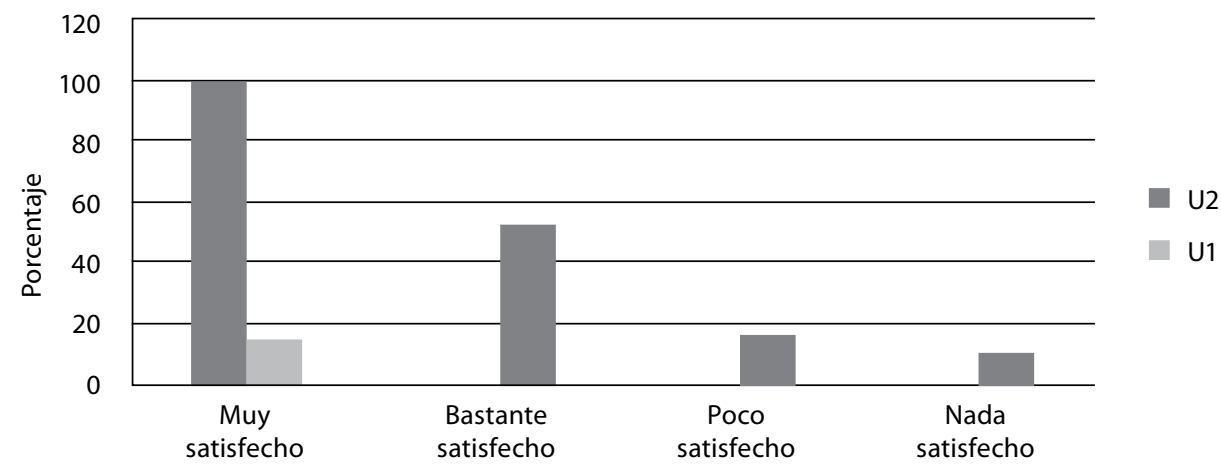

Gráfico 7

¿Cuál es el nivel de satisfacción con el lugar de trabajo en comparación con otras universidades donde ha trabajado? Fuente: elaboración propia, a partir de datos de la investigación

factores higiénicos. Se sienten mal remunerados en comparación con otras universidades, lo cual es una variable que depende de la normatividad vigente o del estatuto docente de cada institución. Para las instituciones públicas, la remuneración de los docentes se establece con base en lo estipulado en el Decreto 1279 de 2002, con una escala salarial determinada según los títulos de estudios universitarios, el escalafón docente, la experiencia y la productividad académica (repartida entre puntos salariales y bonificaciones).

En cambio, en la U2, la remuneración es concebida por la institución según lo manifiesta la coordinadora de la siguiente forma:

En este aspecto, la universidad motiva fuertemente a los docentes, pues tiene una de las tarifas más altas en cuanto a la remuneración de los mismos. En la universidad, hay un estatuto que cataloga por formación y este establece la remuneración, lo cual motiva a los docentes a continuar su proceso de formación.
Lo que no existe en términos de remuneración es el reconocimiento económico de bonos o puntos de acuerdo al número de papers publicados o libros, y esta no va a existir, debido a que dentro del contrato esta es una de las funciones que desde la investigación el docente debe cumplir. En este caso, el reconocimiento no es económico, es de otro tipo como: publicaciones, lanzamientos, regalías, ascenso de categorías, etc., pues la universidad aborda el proceso de investigación desde una mirada responsable que rechaza el mercantilismo de la producción de conocimiento, asumiéndola como una actividad académica responsable.

Con relación a los espacios y condiciones ambientales del trabajo, los docentes de la U2 reparten sus percepciones, muchos de ellos manifiestan estar parcialmente en desacuerdo. En el caso de los docentes de la U1, la insatisfacción es más marcada (gráfico 8). En este tema, la directora del programa de contaduría pública de la U1 dice que: 
MOTIVACIÓN DE LA LABOR DOCENTE / D. CAMARGo / 437

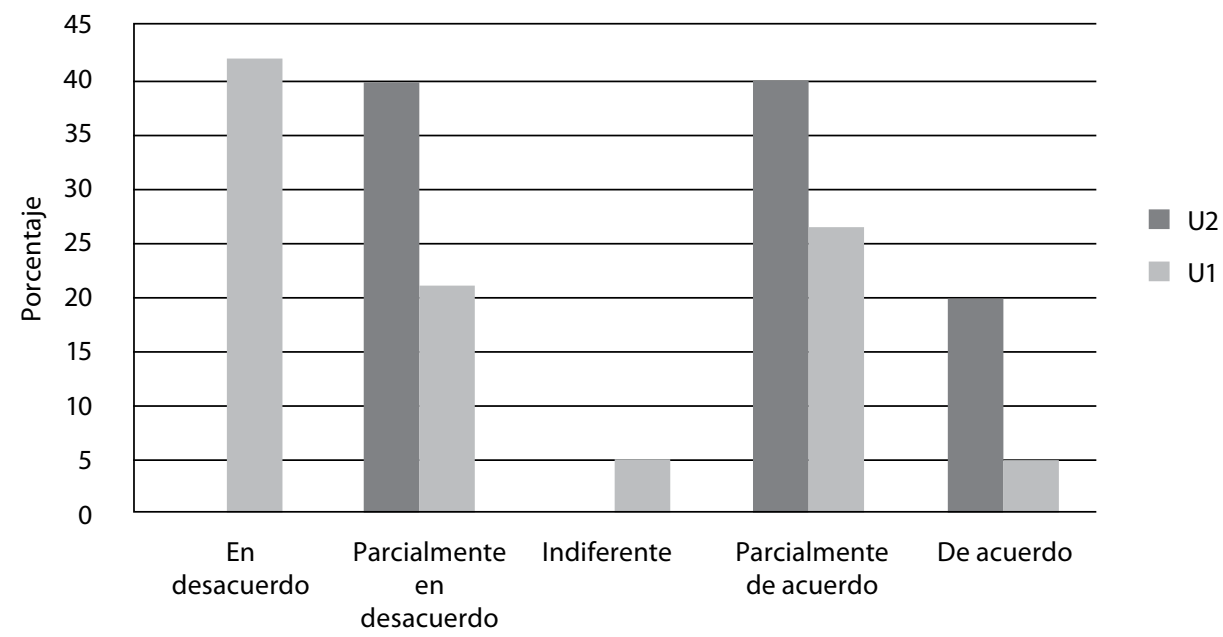

Gráfico 8

¿Su puesto de trabajo es el adecuado para las condiciones de trabajo?

Fuente: elaboración propia, a partir de datos de la investigación

Los puestos de trabajo, si bien es cierto no son los más cómodos, la Universidad ha venido mejorando, porque antes no teníamos un puesto, nos tocaba en las aulas de sistemas. No existía el acceso a las tecnologías e internet y demás. En cambio, ahora se tiene puesto.

\section{Fortalezas:}

- A los docentes en sus puestos de trabajo se les proporciona silla, escritorio, cajoneras y tecnología en su ambiente de trabajo, en un lugar adecuado en luz para el desarrollo de sus actividades.

Debilidades:

- Debía existir una sala de profesores separada de los directores de programa.

- Los profesores debían de tener un lugar un poco más amplio para la atención a los estudiantes.

- Falta privacidad en los puestos de trabajo.
A propósito de los docentes de la U2 que manifiestan estar de acuerdo con los factores ambientales, la directora dice que:

Desde la ergonomía, en términos de las condiciones que le permitan una didáctica adecuada a la hora de cumplir su función docente, el docente cuenta con unos salones que lo capacitan para llevar una didáctica adecuada, ofreciéndose los espacios adecuados y los equipos tecnológicos necesarios que posibilitan su labor.

Los docentes que cumplen funciones de investigación y de extensión, encuentran una motivación grande con respecto a los temas de la disposición física, pues desde la autonomía tienen la posibilidad de escoger el espacio en donde realizan sus funciones, es decir, que no existe presión de cumplimiento de horarios y permanencia física, ya 
que pueden hacer uso de las instalaciones de la universidad (bibliotecas, etc.), o pueden hacer uso de su tiempo en espacios que se encuentra fuera de la universidad como su casa $\mathrm{u}$ otras instalaciones. Considero que este aspecto les ofrece una motivación extra en tanto que no deben cumplir horarios específicos, sino que pueden realizar estas funciones de acuerdo a su disponibilidad de tiempo en los horarios que crean convenientes.

A partir de lo anterior se ve que según la teoría de Frederick Herzberg, Bernard Mausner y Barbara Bloch Snyderman (1959), satisfacer los factores de higiene no motiva al docente en sí, aunque las mejoras en el sueldo o el puesto de trabajo pueden reducir levemente la insatisfacción. Sí es un hecho que ambos grupos de docentes se sienten en general satisfechos con su trabajo como docentes, lo que deja ver que su motivación está latente, pues si se quiere motivar, se deben diseñar estrategias que aumenten la motivación, considerando las oportunidades de desarrollo de logro (producción académica), por medio de la autonomía (posibilidad de proponer aportes al currículo y a los planes de estudio), la responsabilidad (flexibilidad laboral) y el reconocimiento personal (ascensos en el escalafón, premios).

Desde esta perspectiva, la motivación se debe centrar en aquellos factores que permiten el desarrollo profesional (Furnham, Eracleous \& Chamorro-Premuzic, 2009). Por esta vía se pueden explicar los resultados que conforman la motivación de los docentes de la U2, que, en últimas, están centrados en temas como el reconocimiento al trabajo y el aporte que manifiestan han hecho en las construcciones del currículo y el proyecto educativo (gráfico 9). Esto se refuerza con lo que dicen el informe de acreditación y la entrevista a la coordinadora, cuando manifiestan:

En cuanto al clima laboral, es muy benéfico en sus ramas o disciplinas de trabajo, ya que desde la política institucional de autonomía del docente, por supuesto enmarcada en los objetivos de la institución, con un apoyo fuerte en el campo pedagógico y en los temas de evaluación y demás, los docentes tienen la posibilidad de autonomía de un lado y de un apoyo fuerte por los estamentos que componen el programa docente.

(...) Considero que más que un escritorio y una posibilidad de tener un equipo, es más importante la flexibilidad, la autonomía, el acceso a materiales, formación y capacitación permanente el apoyo del equipo de trabajo, el reconocimiento de la universidad en escenarios internacionales y nacionales por el reconocimiento que ha adquirido la universidad, pues el respaldo de la universidad como una entidad fuerte también le da al docente una tranquilidad.

Los logros y las acciones en términos motivacionales para el cumplimiento de los objetivos académicos de los profesores están contenidos en el discurso institucional. Para este trabajo, tal discurso descansa en los informes de acreditación (factor docente, características 10 a 17) y en las respuestas a las entrevistas a los directivos de ambos programas. 
MOTIVACIÓN DE LA LABOR DOCENTE / D. CAMARGo / 439

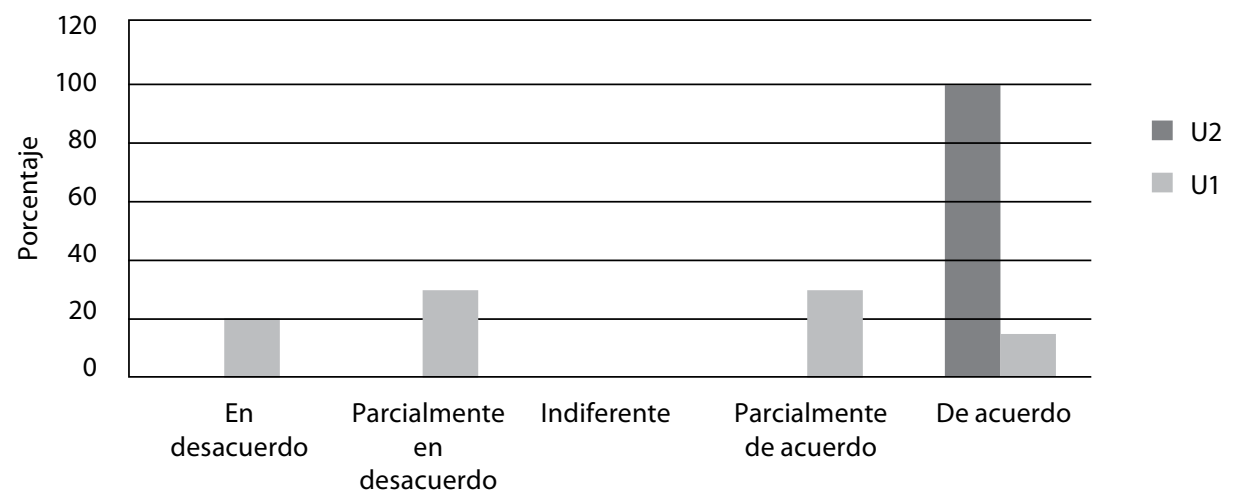

Gráfico 9

¿Considera que su trabajo está suficientemente reconocido y considerado por su jefe o superiores?

Fuente: elaboración propia, a partir de datos de la investigación

Desde un primer análisis de este discurso se logró identificar que el programa de contaduría pública de la U1 presenta los resultados con base en las encuestas y análisis documentales de una forma más descriptiva, en torno a los resultados de estos instrumentos, por lo cual el discurso es más impersonal, mientras no pone de manifiesto literalmente los resultados de las encuestas de percepción, ya que el análisis se hace desde el marco global de los lineamientos de acreditación del CNA ${ }^{6}$. Por otro lado, el discurso que propone el programa de la U2 es más explicativo, pues deja ver las percepciones y acciones de forma concreta y literal para justificar el cumplimiento de cada característica en concordancia con los lineamientos de acreditación nacional.

En este sentido, se puede corroborar que en sus discursos y metodologías de análisis particulares, ambas universidades visibilizan las necesidades de los docentes de acuerdo con las funciones

6 La acreditación que otorga el Consejo Nacional de Acreditación (CNA) es el reconocimiento por parte del Estado colombiano de la calidad de instituciones de educación superior y de sus programas académicos. que realizan y las condiciones en las cuales se desempeñan, por lo cual se vuelven un instrumento vital para la gestión de estas organizaciones educativas y el mejoramiento continuo del proceso de enseñanza-aprendizaje en lo referente a los procesos motivacionales del docente.

En la misma dirección, las entrevistas a los directivos de ambos programas encarnan dos discursos. Uno de ellos es pedagógico, no mercantil y se centra en el docente; esto se desprende de las respuestas de la coordinadora en la U2, que hace explícito que:

En términos de función docente neta, una motivación especial es la estabilidad de los docentes que da la universidad: en términos de reconocimiento de hacer bien el trabajo, que va más allá de las relaciones sociales que pueda generar. Es decir, que aunque cambien las administrativas, etc., el docente puede estar tranquilo en cuanto a que desde que haga bien su trabajo, su estabilidad laboral va a estar asegurada. Esto genera mucha tranquilidad y 
motivación, porque el que está aquí es considerado un docente capaz y bueno en todas las funciones que se enmarcan dentro de su labor.

En cambio, el segundo discurso para la U1 está más centrado en los factores higiénicos y en menor medida en los motivadores; al comparar las condiciones que tenían que afrontar los docentes para desempeñar sus funciones entre el pasado y el presente, exhibe los avances logrados por la institución educativa. Esto lo hace explícito la directora de programa, cuando afirma que los factores que motivan a los docentes son:

- Reconocer por mérito los ascensos dentro de la organización (organigrama de la Universidad).
- Realizar intercambio entre universidades nacionales e internacionales, y así mismo los docentes pueden valorar más la institución porque tienen otros referentes.

- Tener todos los materiales de trabajo (marcadores, libros, etc.) para cada uno de forma más adecuada.

- Tener mejores espacios físicos para atención a los estudiantes y para su práctica laboral.

- Conferencias para mejorar actitudes y aptitudes y de formación humanística.

A manera de resumen, la tabla 4 muestra los resultados generales de encuestas y entrevistas para cada categoría de análisis.

\begin{tabular}{|c|c|c|}
\hline $\begin{array}{c}\text { Programa de } \\
\text { contaduría pública }\end{array}$ & $\begin{array}{c}\text { Percepción de los docentes } \\
\text { (encuesta) }\end{array}$ & $\begin{array}{c}\text { Percepción de los jefes de } \\
\text { programa (entrevista) }\end{array}$ \\
\hline \multicolumn{3}{|c|}{ Remuneración } \\
\hline $\mathrm{U} 1$ & $\begin{array}{l}\text { El 40\% de los encuestados considera que } \\
\text { su trabajo no está bien remunerado en } \\
\text { comparación con los otros. } \\
\text { El 38\% está en consonancia con los sueldos } \\
\text { que hay en su Universidad. } \\
\text { El 37\% está de acuerdo en que hay igualdad } \\
\text { en la remuneración según los géneros. } \\
\text { El 48\% recibe en promedio entre } 3 \text { y } 5 \\
\text { salarios mínimos. } \\
\text { El 58\% recibe ingresos únicamente de la } \\
\text { actividad docente. }\end{array}$ & \\
\hline $\mathrm{U} 2$ & $\begin{array}{l}\text { El } 60 \% \text { está de acuerdo en que su trabajo es } \\
\text { bien remunerado en comparación con otros. } \\
\text { El } 60 \% \text { está de acuerdo en que su sueldo está } \\
\text { en consonancia con los sueldos que hay en su } \\
\text { Universidad. } \\
\text { El } 60 \% \text { está de acuerdo en que hay igualdad } \\
\text { en la remuneración según el género. } \\
\text { El } 60 \% \text { recibe en promedio entre } 6 \text { a } 8 \\
\text { salarios mínimos. } \\
\text { El } 40 \% \text { recibe ingresos únicamente de la } \\
\text { actividad docente. }\end{array}$ & $\begin{array}{l}\text { En este aspecto, la universidad motiva } \\
\text { fuertemente a los docentes, pues tiene } \\
\text { una de las tarifas más altas en cuanto } \\
\text { a la remuneración de los mismos. En } \\
\text { la Universidad, hay un estatuto que } \\
\text { cataloga por formación y este establece la } \\
\text { remuneración, lo cual motiva a los docentes } \\
\text { a continuar su proceso de formación. }\end{array}$ \\
\hline
\end{tabular}




\begin{tabular}{ccc}
\hline $\begin{array}{c}\text { Programa de } \\
\text { contaduría pública }\end{array}$ & $\begin{array}{c}\text { Percepción de los docentes } \\
\text { (encuesta) }\end{array}$ & $\begin{array}{c}\text { Percepción de los jefes de } \\
\text { programa (entrevista) }\end{array}$ \\
\hline \multicolumn{3}{c}{ Condiciones ambientales } \\
\hline
\end{tabular}

El 68\% considera que su puesto de trabajo no tiene la privacidad requerida para el trabajo que realiza.

El 58\% está en desacuerdo en que hay espacios adecuados y condiciones para el trabajo en equipo.

U1
El 44\% está de acuerdo en que tiene suficiente luz en su lugar de trabajo.

El 52\% está de acuerdo en que la temperatura del trabajo es la adecuada.

El 53\% está de acuerdo en que tiene el espacio requerido para garantizar las condiciones de trabajo.

El 40\% considera que su puesto de trabajo tiene la privacidad requerida para el trabajo que realiza.

El 40\% está de acuerdo en que hay espacios adecuados y condiciones para el trabajo en equipo.

El 100\% está de acuerdo en que tiene suficiente luz en su lugar de trabajo.

El 80\% está de acuerdo en que la temperatura del trabajo es la adecuada.

El 40\% está de acuerdo en que tiene el espacio requerido para garantizar las condiciones de trabajo y el desarrollo de sus funciones.
Los puestos de trabajo, si bien es cierto no son los más cómodos, la Universidad ha venido mejorando, porque antes no teníamos un puesto, nos tocaba en las aulas de sistemas. No existía el acceso a las tecnologías e internet y demás. En cambio, ahora se tiene puesto.

Desde la ergonomía, en términos de las condiciones que le permitan una didáctica adecuada a la hora de cumplir su función docente, el docente cuenta con unos salones que lo capacitan para llevar una didáctica adecuada, ofreciéndose los espacios adecuados y los equipos tecnológicos necesarios que posibilitan su labor.

\section{Posibilidades de creatividad e iniciativa}

El 59\% está de acuerdo en que tiene la suficiente autonomía en su trabajo.

El 36\% está de acuerdo en que sus ideas son escuchadas por sus superiores.

El 38\% está de acuerdo en que su trabajo es rutinario.

El 40\% y el 30\% están parcialmente de acuerdo en que se sienten partícipes en la construcción del proyecto educativo del programa y del currículo.

El 41\% está de acuerdo en que su trabajo ha transformado su entorno social.

El 35\% está en desacuerdo en que en su campo de trabajo hay posibilidad de acceder a otros campos superiores o de cambiar de dependencia.
- Capacitaciones en temas de actualidad.

- Se contratan egresados.

La Universidad reconoce a sus docentes en:

- Auxilio para estudios avanzados (maestrías, doctorados).

- Reconocimiento por mérito (condecoraciones). 


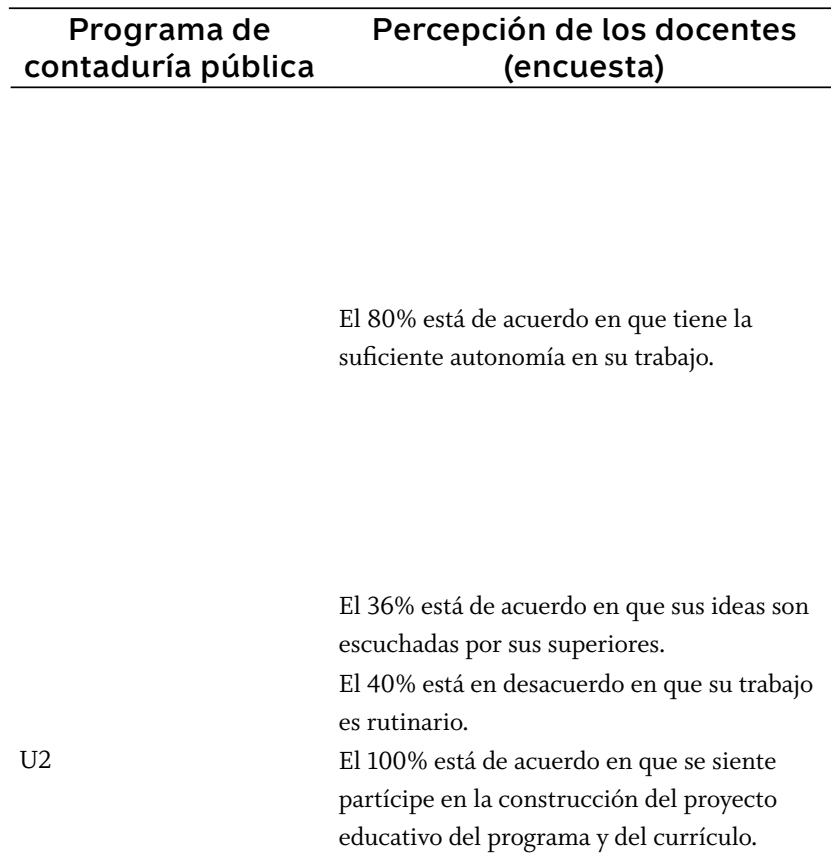

En cuanto a los tutores de las prácticas empresariales, en su mayoría son docentes de la universidad. Este semestre se prefirió que sean de vinculación hora cátedra para que se dediquen por completo a estas horas, ya que se pagan como una actividad independiente y se puede tener una dedicación total, buscando que los profesores de tiempo completo fortalezcan sus procesos de investigación dedicando más tiempo a la misma.

El 40\% está parcialmente de acuerdo en que en su campo de trabajo hay posibilidad de acceder a otros campos superiores o de cambiar de dependencia.

\section{Reconocimiento}

El 30\% está parcialmente en desacuerdo en que su trabajo está suficientemente reconocido por su jefe o profesores. El 38\% está parcialmente de acuerdo en que el cargo que ocupa en la Facultad es acorde con la experiencia que posee.

El 52\% está de acuerdo en que su cargo es acorde con su formación académica.
Factores que motivan a los docentes:

Reconocer por mérito los ascensos dentro de la organización (organigrama de la Universidad).

Realizar intercambio entre universidades nacionales e internacionales, y así mismo los docentes pueden valorar más la institución porque tienen otros referentes. 
MOTIVACIÓN DE LA LABOR DOCENTE / D. CAMARGo / 443

\begin{tabular}{cc}
\hline $\begin{array}{c}\text { Programa de } \\
\text { contaduría pública }\end{array}$ & $\begin{array}{c}\text { Percepción de los docentes } \\
\text { (encuesta) }\end{array}$ \\
\hline
\end{tabular}

El 25\% está en desacuerdo y es indiferente, en que sus funciones son valoradas desde otras dependencias.

U1

El 100\% está de acuerdo en que su trabajo está suficientemente reconocido por su jefe o profesores.

El 100\% está de acuerdo en que el cargo que ocupa en la facultad es acorde con la experiencia que posee.

El 52\% está de acuerdo en que su cargo es acorde con su formación académica.

El 60\% está de acuerdo en que sus funciones son valoradas desde otras dependencias.

\section{Percepción de los jefes de programa (entrevista)}

Tener todos los materiales de trabajo (marcadores, libros, etc.) para cada uno de forma más adecuada.

Tener mejores espacios físicos para atención a los estudiantes y para su práctica laboral.

Conferencias para mejorar actitudes y aptitudes y de formación humanística.

Factores que motivan a los docentes.

Por un lado, el cumplimiento de los términos contractuales, esto hace que el docente se sienta seguro y apoyado en ese sentido.

Por otro lado, factores como el apoyo a la formación, por ejemplo, los cursos de idiomas, pues el hecho de que tengan posibilidades de formación y de capacitación motiva mucho a los docentes. También tener el acceso a la información, bases de datos, textos que son complicados de adquirir, por su costo o su dificultad de conseguir, también esto motiva mucho a los docentes en el proceso de investigación.

Considero que más que un escritorio y una posibilidad de tener un equipo, es más importante la flexibilidad, la autonomía, el acceso a materiales, formación y capacitación permanente, el apoyo del equipo de trabajo, el reconocimiento de la universidad en escenarios internacionales y nacionales por el reconocimiento que ha adquirido la universidad, pues el respaldo de la universidad como una entidad fuerte también le da al docente una tranquilidad.

\section{Satisfacción en el trabajo}

El 50\% está bastante satisfecho con el

lugar de trabajo en comparación con otras

U1 universidades donde ha trabajado.

El 70\% está satisfecho con su desempeño en

la Universidad. 


\begin{tabular}{lll}
\hline $\begin{array}{c}\text { Programa de } \\
\text { contaduría pública }\end{array}$ & \multicolumn{1}{c}{$\begin{array}{c}\text { Percepción de los docentes } \\
\text { (encuesta) }\end{array}$} & $\begin{array}{c}\text { Percepción de los jefes de } \\
\text { programa (entrevista) }\end{array}$ \\
\hline & $\begin{array}{l}\text { El 100\% está muy satisfecho con el lugar } \\
\text { de trabajo en comparación con otras }\end{array}$ & \\
U2 & universidades donde ha trabajado. \\
& El 80\% está satisfecho con su desempeño en & \\
& la Universidad. \\
\hline
\end{tabular}

Tabla 4

Resumen de resultados por categorías de análisis

Fuente: elaboración propia, a partir de datos de la investigación

\section{Consideraciones finales}

La motivación tiene diversas teorías; la de Frederick Herzberg, Bernard Mausner y Barbara Bloch Snyderman (1959), que se usó para esta investigación, permitió identificar las motivaciones de los docentes y encontrar coincidencias con lo expresado por directivos e informes de acreditación.

Las entrevistas a los directivos de los programas arrojaron que en el U2 se privilegian los aspectos pedagógicos, que están estrechamente relacionados con los motivadores sin minimizar los efectos de los factores higiénicos. En cambio, en la U1, los factores higiénicos se identifican por encima de los motivadores.

Estos hallazgos coinciden con los resultados de las encuestas, de los que se concluye que en ambas universidades los docentes están motivados, lo que muestra que en general están satisfechos como profesores de tiempo completo, a pesar de que otros factores les produzcan insatisfacción.

En el caso de la U1, los docentes no manifiestan una tendencia clara respecto a su satisfacción con el lugar de trabajo (institución educativa) y con el reconocimiento que hacen sus jefes de su desempeño, ya que los resultados de las encuestas están muy repartidos entre las opciones: nada satisfecho y muy satisfecho. En la remuneración sí se marcan tendencias, ya que manifiestan en términos comparativos que su trabajo está peor remunerado que otros, que sus escalas salariales son bajas y que dependen en mayor medida de los sueldos que perciben de la institución educativa para la que trabajan. Estos aspectos que generan insatisfacción no terminan por afectar la motivación de estos profesores.

Por su parte, en la U2 los docentes manifiestan tener un alto grado de satisfacción con la institución educativa para la que trabajan. Por un lado, porque su trabajo es reconocido por sus jefes $y$, por otro, por la remuneración. A este respecto dependen menos de lo que les paga la universidad (con respecto a sus ingresos mensuales). Además, manifiestan que su labor está mejor remunerada, respecto de otros posibles trabajos, y en términos comparativos, sus salarios son más altos que los de su contraparte en este análisis.

Las conclusiones presentadas son acordes a lo planteado en la literatura por Andre Bishay (1996) y Paul R. Pintrich \& Elisabeth V. de Groot (1990), al reconocer que los motivadores influyen en el docente y repercuten en su quehacer. Esto tiene qué ver pues con las capaci- 
dades, expectativas, autoeficacia, autonomía y autorrealización, que provienen de las relaciones laborales y organizacionales, porque como lo explica Carlos Manuel Álvarez de Zayas (1992), el comportamiento de los actores involucrados en el proceso educativo se da gracias a la relación de factores externos (condiciones físicas y de interacción con agentes educativos) e internos (elementos humanos que componen las prácticas dentro de la institución educativa), por lo que si hablamos de un servicio educativo y que es el resultado de una coproducción (Rubalcaba-Bermejo, 2008) de actores en la escuela, se hace necesario, según María Alejandra Zangara (1998), tener en cuenta los intereses y motivaciones de cada uno de los involucrados, para que la organización y el docente estén en condiciones de responder a las de la sociedad.

Con esto se pretende reivindicar el poder de la motivación como herramienta pedagógica y didáctica en la práctica docente, tema no tan trabajado en la investigación en educación. De ahí la importancia de seguir adelantando trabajos desde el enfoque interpretativo de las subjetividades de los docentes, en especial en educación superior y programas de contaduría pública.

\section{Referencias}

Ajello, Anna María (2003). La motivación para aprender. En Clotilde Pontecorvo (coord.). Manual de psicología de la educación, 251271. Madrid: Popular.

Álvarez de Zayas, Carlos Manuel (1992). La escuela en la vida. La Habana: Edición Comercial Mercadú.
Baltodano-Zúñiga, Víctor Julio \& BadillaAlvarado, Ana Rita (2009). Aportes de la administración moderna a la gerencia educativa. Revista Electrónic@ Educare,XIII (2), 147-158. Disponible en: http://www. revistas.una.ac.cr/index.php/EDUCARE/ article/view/1501/1421

Bishay, Andre (1996). Teacher Motivation and Job Satisfaction: A Study Employing the Experience Sampling Method. Journal of Undergraduate Sciences, 3, 147-154. Disponible en: https://www.hcs.harvard. edu/ jus/0303/bishay.pdf

Cazau, Pablo (2006). Introducción a la investigación en ciencias sociales. Buenos Aires.

Colombia (2002). Decreto 1279 de 2002, por el cual se establece el régimen salarial y prestacional de los docentes de las universidades estatales, 19 de junio de 2002. Disponible en: http://www. mineducacion.gov.co/1621/articles-86434_ Archivo_pdf.pdf

Dahnke, Gordon L. (1989). Investigación y comunicación. En Carlos FernándezCollado \& Gordon L. Dahnke (comps.). La comunicación humana: ciencia social. México: Editorial McGraw-Hill.

Durkheim, Émile (2000). Educación y sociología. Barcelona: Ediciones Península. Furnham, Adrian; Eracleous, Andreas \& Chamorro-Premuzic, Tomás (2009). Personality, Motivation and Job Satisfaction: Hertzberg Meets the Big Five. Journal of Managerial Psychology, 24 (8), 765-779. DOI: http://dx.doi. org/10.1108/02683940910996789 
Gairín-Sallán, Joaquín (1988-1989). El objeto de la organización escolar. Educar, 14-15, 167-187. Disponible en: https://ddd.uab.cat/ pub/educar/0211819Xn14-15/0211819Xn1415p167.pdf

García-Álvarez, Santiago (2015). Elementos de política de gestión en Henry Mintzberg. (Tesis doctoral). Universidad de Navarra, Pamplona. Disponible en: http://dadun. unav.edu/bitstream/10171/38521/1/Tesis_ SantiagoGarciaAlvarez.pdf

García-Jiménez, Marlon David (2016). Modelos de conocimiento científico escolar en un grupo de maestros de programas universitarios de contaduría pública. Revista Sophia, 12 (1), 85-105. Disponible en: http://revistas.ugca.edu.co/index.php/ sophia/article/view/448/719

Hernández, Gaspar (25 de noviembre de 2013). Docente, profesor, educador y maestro. El Heraldo, sección Columnas de opinión. Disponible en: http://www.elheraldo.co/ columnas-de-opinion/docente-profesoreducador-y-maestro-133508

Hernández-Sampieri, Roberto; FernándezCollado, Carlos \& Baptista-Lucio, Pilar (2006). Metodología de la investigación. México: McGraw-Hill, Interamericana Editores. Disponible en: https:// competenciashg.files.wordpress. com/2012/10/sampieri-et-al-metodologiade-la-investigacion-4ta-edicionsampieri-2006_ocr.pdf

Herzberg, Frederick; Mausner, Bernard \& Snyderman, Barbara Bloch (1959). The Motivation to Work. New Brunswick, London: Transaction Publishers.
Karabenick, Stuart A. \& Conley, AnneMarie (2011). Teacher Motivation for Professional Development. Math and Science Partnership - Motivation Assessment Program, MSPMAP, University of Michigan, Ann Arbor, MI 48109. Disponible en: http://mspmap. org/wp-content/uploads/2012/01/TeacherPDM.pdf

León-Paime, Edison Fredy (2008). Las facultades de la modernización: contexto de aparición de los programas de contaduría pública en Colombia. Revista de la Facultad de Ciencias Económicas, Universidad Militar Nueva Granada, 16 (1), 41-58. Disponible en: http://www.umng.edu.co/web/revistas/ revista-fac.-ciencias-economicas/espanol/ publicaciones-anteriores/revista-vol-xvino.1, https://dialnet.unirioja.es/descarga/ articulo/4192022.pdf

León-Paime, Edison Fredy (2009). La educación contable en el contexto anglosajón: una mirada a los años de construcción de comunidad. Cuadernos de Contabilidad, 10 (27), 219-245. Disponible en: http://revistas.javeriana.edu.co/index. php/cuacont/article/view/3208/2440

León-Paime, Edison Fredy (2011). Ser y comprender al docente contable: exploraciones autoetnográficas. Cuadernos de Contabilidad, 12 (30), 179-210.

Disponible en: http://revistas.javeriana. edu.co/index.php/cuacont/article/ view/3115/2289

León-Paime, Edison Fredy (2013). La investigación en educación contable: breve historia y revisión internacional. Revista Lúmina, 14, 228-261. Disponible en: http://revistasum. 
umanizales.edu.co/ojs/index.php/Lumina/ article/viewFile/1087/1192

Loaiza-Robles, Fabiola (2011). Producción académica sobre educación contable en Colombia 2000-2009: incidencia de la pedagogía crítica. Revista Lúmina, 12, 172194. Disponible en: http://revistasum. umanizales.edu.co/ojs/index.php/Lumina/ article/download/698/821

Macías, Hugo A. (2013). Vínculos de la investigación contable interpretativa con la producción académica colombiana: avances y oportunidades. Cuadernos de Contabilidad, 14 (35), 699-727. Disponible en: http:// cuadernosdecontabilidad.javeriana.edu.co/ vol14_n_35/vol14_35_12.pdf

Macías, Hugo A. \& Patiño-Jacinto, Ruth Alejandra (2014). Evolución de las revistas contables colombianas: de la reflexión a la investigación. Revista Contaduría Universidad de Antioquia, 64, 13-48. Disponible en: https://aprendeenlinea. udea.edu.co/revistas/index.php/cont/article/ view/23160/19056

Martínez-González, Raquel-Amaya (2007). La investigación en la práctica educativa: Guía metodológica de investigación para el diagnóstico y evaluación en los centros docentes. Madrid: Ministerio de Educación y Ciencia Dirección General de Educación, Formación Profesional e Innovación Educativa. Disponible en: http://vozyverso. uacj.mx/Docentes/Invedu/Textos/2.pdf

McClelland, David C. (1989). Estudio de la motivación humana. Madrid: Narcea. Monje-Álvarez, Carlos Arturo (2011). Metodología de la investigación cuantitativa y cualitativa. Guía didáctica. Neiva: Universidad Surcolombiana. Disponible en: https://carmonje.wikispaces.com/file/view/ Monje+Carlos + Arturo+-+Gu\%C3\%ADa+ $\operatorname{did} \% \mathrm{C} 3 \% \mathrm{~A} 1 \mathrm{ctica}+$ Metodolog\%C3\%ADa $+\mathrm{d}$ e+la+investigaci\%C3\%B3n.pdf

Okuda-Benavides, Mayumi \& Gómez-Restrepo, Carlos (2005). Métodos en investigación cualitativa: triangulación. Revista Colombiana de Psiquiatría, XXXIV (1), 118124. Disponible en: http://www.scielo. org.co/scielo.php?script $=$ sci_arttext\&pid =S0034-74502005000100008

Pasillas-Valdez, Miguel Ángel (1992). Pedagogía, educación, formación. Revista Multidisciplin@de la Facultad de Estudios Superiores Acatlán, Universidad Nacional Autónoma de México, UNAM, 02, 143-158. Disponible en: http://www.acatlan.unam. $\mathrm{mx} /$ repositorio/general/Multidisciplina/ Segunda-Epoca/multi-1992-02-11.pdf Pintrich, Paul R. \& Groot, Elisabeth V. de (1990). Motivational and Self-Regulated Learning Components of Classroom Academic Performance. Journal of Educational Psychology, 82 (1), 33-40. Disponible en: http://rhartshorne.com/ fall-2012/eme6507-rh/cdisturco/eme6507eportfolio/documents/pintrich\%20and $\% 20$ degroodt\%201990.pdf

Ramió, Carles (1999). Teoría de la organización y administración pública. Madrid: Tecnos.

Ramió, C. \& Ballart, Xavier (1993). Teoría de la organización. Madrid: Ministerio para las Administraciones Públicas.

Rasheed, Muhammad Imran; Aslam, Hassan Danial \& Sarwar, Shakeel (2010). 
Motivational Issues for Teachers in Higher

Education: A Critical Case of IUB. Journal of Management Research, 2 (2), E3. Disponible en: http://pakacademicsearch.com/pdffiles/ech/127/1-23\%20Vol\%202,\%20No\%20 $2 \% 20(2010) \cdot p d f$

Robbins, Stephen R. \& DeCenzo, David A. (2002). Fundamentos de administración: conceptos esenciales y aplicaciones. México: Pearson.

Rubalcaba-Bermejo, Luis (2008). Los servicios en la Economía Europea: desafíos e implicaciones de política económica. Madrid: Fundación Rafael del Pino.

Stake, Robert E. (2007). Investigación con estudio de casos. Madrid: Ediciones Morata.

Visser-Wijnveen, Gerda J.; Stes, Ann \& Petegem, Peter van (2012). Development and Validation of a Questionnaire Measuring Teachers' Motivations for Teaching in Higher Education. Higher Education (Springer Science+Business), 64 (3), 421-436.
Zangara, María Alejandra (1998). La incorporación de las nuevas tecnologías de la información y la comunicación a los diseños curriculares. Algunos temas críticos. IV Congreso de Redes Iberoamericanas de la Informática Educativa. Brasilia-Brasil, 20 al 23 de octubre, 1998. Disponible en: http:// www.ufrgs.br/niee/eventos/RIBIE/1998/ pdf/com_pos_dem/116.pdf

- Fecha de recepción: 17 de abril de 2016

- Fecha de aceptación: 23 de julio de 2016

- Disponible en línea: 14 de diciembre de 2016

\section{Para citar este artículo}

Camargo-Mayorga, David Andrés (2016). Motivación de la labor docente: un estudio de caso de dos programas de contaduría pública en Bogotá. Cuadernos de Contabilidad, 17 (44), 421-448. https:// doi.org/10.11144/Javeriana.cc17-44.mlde 